\title{
Universidade de Coimbra instituição educativa do Império Lusitano: análise da reforma joanina no século XVI
}

\section{University of Coimbra educational institution of the Lusitanian Empire: analysis the johannite reform in the 16th century}

\section{Universidad de Coimbra, institución educativa del Imperio Lusitano: análisis de la reforma joanina en el siglo XVI}

\author{
Luciana de Araújo Nascimento-Guaraldo' \\ Célio Juvenal Costa" \\ 'Universidade Estadual de Maringá, Paraná - Brasil. E-mail: Iu_araujo102@hotmail.com.br \\ "Universidade Estadual de Maringá, Paraná - Brasil. E-mail: celio_costa@terra.com.br
}

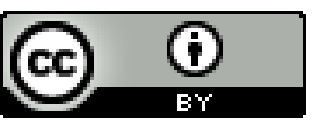

Educação: teoria e prática, Rio Claro, SP, Brasil - eISSN: 1981-8106

Está licenciada sob Licença Creative Common

Resumo: Este texto tem o objetivo de apresentar algumas reflexões referentes à reforma da Universidade de Coimbra, realizada no reinado de D. João III, século XVI. Mediante a análise desse período chamamos atenção para dois aspectos presentes na vida da instituição: contratação docente e reorganização financeira. Percebemos que esses dois aspectos podem ser compreendidos como algumas das diretrizes da Coroa portuguesa para reformar a Universidade de Coimbra. Por meio da analise e apresentação das fontes documentais, cartas e alvarás remetidos à Universidade pela Coroa, procuramos demonstrar ao leitor a importância desse momento para a história das instituições de ensino não apenas portuguesas, mas também brasileiras, já que depois desse fato a Universidade de Coimbra passou a ser considerada o centro de formação do Império, responsável pela formação dos quadros dirigentes da sociedade, tanto no plano eclesiástico como civil, no reino e em territórios ultramarinhos. Os documentos analisados apontam que investigar esse momento histórico da Universidade de Coimbra colabora na compreensão dos objetivos de formação humana que se pretendia naquele período. 
Palavras-chave: Universidade de Coimbra. Reforma. D. João III. Contratação docente. Reorganização financeira.

\begin{abstract}
This paper aims to present some reflections on the reform of the University of Coimbra, which took place in the reign of King John III, 16th century. By examining this period we call attention to two aspects present in the life of the institution: teacher recruitment and financial reorganization. We realize that these two aspects can be understood as some of the guidelines of the Portuguese Crown to reform the University of Coimbra. Through the analysis and presentation of documentary sources, letters and permits sent to University by the Crown, we seek to demonstrate to the reader the importance of that moment to the story of educational institutions not only in Portugal but also in Brazilian ones, since then this fact University of Coimbra came to be regarded as the training centre of the Empire, responsible for the training of senior managers of the company, both in ecclesiastical plan as a civilian in the Kingdom and in overseas territories. The documents analyzed point out that to investigate that Historical period of University of Coimbra collaborates to understanding of the goals in terms of human formation at that period.
\end{abstract}

Keywords: University of Coimbra. Reform. D. João III. Teacher recruitment. Financial reorganization.

Resumen: Este texto tiene el objetivo de presentar algunas reflexiones referentes a la reforma de la Universidad de Coimbra, realizada en el reinado de D. João III, siglo XVI. Mediante el análisis de ese período llamamos la atención para dos aspectos presentes en la vida de la institución: contratación docente y reorganización financiera. Notamos que estos dos aspectos pueden comprenderse como algunas de las directrices de la Corona portuguesa para reformar la Universidad de Coimbra. Por medio del análisis y la presentación de las fuentes documentales, cartas y licencias remitidas a la Universidad por la Corona, procuramos demostrar al lector la importancia de ese momento para la historia de las instituciones de enseñanza no apenas portuguesas, sino también brasileñas, ya que después de ese hecho la Universidad de Coimbra pasó a ser considerada el centro de formación del Imperio, responsable por la formación de los cuadros dirigentes de la sociedad, tanto en el plano eclesiástico como en el civil, en el reino y en territorios ultramarinos. Los documentos analizados señalan que investigar ese momento histórico de la Universidad de Coimbra colabora en la comprensión de los objetivos de formación humana que se pretendía en aquel período.

Palabras clave: Universidad de Coimbra. Reforma. D. João III. Contratación docente. Reorganización financiera. 
Meu Santíssimo etc. por que para a conservação e aumento da fé católica e bom governo espiritual e temporal em meus reinos e senhorios é necessário haver muitos letrados e pessoas doutas assim para o bom governo espiritual e temporal deles como para poderem ir e serem enviados as partes da Índia e de Goa e do Brasil e outros de meus senhorios e conquista a pregar e ensinar aos novamente convertidos a fé de nosso Senhor Jesus e assim pregar aos gentios e infiéis das ditas partes para que se converta a nossa Santa fé católica de que se seguira grande serviço de Deus ordenei fazer Universidade e Estudos Gerais na cidade de Coimbra para os quais fiz vir muitos de muitas partes de outras universidades e partes de fora de meus reinos mestres e doutores e (mestres em algumas ciências) em Teologia e Cânones em outras ciências e faculdades aos quais tenho ordenado salários e mantimentos para que hajam de ler e ensinar nos ditos estudos e por que a dita Universidade sendo coisa tão necessária e tão proveitosa e tão a serviço de Deus se não pode sustentar sem ter rendas convenientes para que pelos tempos em diante sejam pagos regentes lentes mestres e doutores que em ela lem é necessário convem muito ser dotada de rendas da dita renda do mosteiro de S. Cruz situado [...] na dita cidade de Coimbra [...] Pelo que peço a vosso Santíssimo por mercê que havendo respeito a essa obra ser de tão grande serviço de Deus e tão proveitosa para a Republica eclesiástica e secular desses reinos e senhorios me queira fazer mercê de anexar a Universidade as ditas rendas e direitos do dito priorado de Santa Cruz [...] (DOCUMENTOS DE D. JOÃO III, 1938, vol. II, p. 229 e 230 , sem grifos no original).

A carta acima transcrita versa sobre o pedido de anexação das rendas do Priorado-Mor do Mosteiro de Santa Cruz à Universidade de Coimbra. Foi enviada ao Papa Paulo III (15341549), em 16 de setembro de 1546, por D. João III (1521-1557), intencionando convencer o Pontífice da importância desses rendimentos às finanças do Estudo.

Acreditamos que o ponto central em que incide essa carta não se relaciona apenas com a anexação das rendas do referido Mosteiro à Universidade, mas sim às ações da Coroa para com a Universidade portuguesa no governo de D. João III ${ }^{1}$.

A opção e a justificativa de principiarmos essa exposição pelo referido documento relacionam-se à relevância das ações da Coroa na história da primeira Universidade portuguesa. Ao analisarmos os documentos, bem como a literatura sobre o referido tema e período, observamos a relevância desse momento tanto para a história da educação portuguesa, e nela a Universidade, como para as raízes da história da educação brasileira, já que foi nessa instituição que se formaram não apenas os membros da elite dirigente do Brasil Colônia, mas também boa parte dos missionários, inclusive jesuítas, que atuaram na educação colonial no dito período.

Por meio das pesquisas realizadas, percebemos que foi no reinado do Piedoso, D. João III, que a Universidade sofreu uma profunda reforma dirigida pela Coroa lusitana. Depois

\footnotetext{
1 O presente trabalho é parte de uma pesquisa concluída a nível de mestrado no campo da História e Historiografia da Educação.
} 
disso, a instituição passou a formar, além dos missionários jesuítas, os dirigentes reais para atuarem em todo o Império português, inclusive no Brasil, na evangelização, catequização e administração dos povos que aqui residiam, os colonos, e daqueles que até então eram desconhecidos, os índios. A Universidade de Coimbra foi a única instituição de ensino superior do Brasil, com quadro completo de todas as faculdades, não somente nos três séculos da Colônia, mas também no início do Império, "Até os começos do século XIX, a universidade do Brasil foi a Universidade de Coimbra, onde iam estudar os brasileiros depois dos cursos no Brasil nos reais colégios dos jesuítas" (TEIXEIRA, 1989, p. 65).

Nesse sentido, acreditamos que as reflexões de Montesquieu em $O$ espírito das leis, livro $\mathrm{XXX}$, quando discorre sobre a teoria das leis feudais entre os francos na relação com o estabelecimento da monarquia, podem colaborar no que aqui pretendemos apresentar. $\mathrm{O}$ autor afirmou: "É um belo espetáculo o das leis feudais. Um carvalho antigo ergue-se, os olhos vêem de longe sua folhagem; ele se aproxima, vê-se o tronco, mas não se percebe suas raízes: é preciso cavar a terra para encontrá-la" (1995, p. 443). Assim, percebemos a história da educação brasileira, representada pelo carvalho, e nela a história da educação no Brasil Colônia, em seus primórdios. Para compreendermos a formação do carvalho é necessário cavar suas raízes, que nada mais são do que a história da educação colonial.

Diante disso, consideramos que o estudo sobre as instituições de ensino lusitana, no referido período, colabora para compreender a formação humana que se objetivava naquele momento histórico. Entre os estabelecimentos educacionais portugueses, enfatizamos o papel exercido pela Universidade de Coimbra, que depois de 1537, após reforma administrativa, pedagógica e financeira, passou a ser centro de referência na formação religiosa, científica e cultural do Império lusitano.

Fundamentados nos documentos coligidos e nas obras historiográficas selecionadas para a estruturação deste texto, apresentamos as relações estabelecidas entre o poder real nas diversas medidas tomadas para transformar a educação portuguesa por meio da reforma da Universidade. Ao longo do artigo, almejamos discorrer acerca das diversas ações da Coroa lusitana para reformar a Universidade, por meio da reorganização financeira e contratação docente. Acreditamos que tais diretrizes estavam profundamente relacionadas com a intenção de tornar a instituição um centro de referência portuguesa na formação cultural, religiosa e científica para todo o Império luso. Essas iniciativas, por sua vez, só podem ser compreendidas se relacionadas ao contexto macro da sociedade portuguesa e aos acontecimentos históricos do século XVI.

Na carta acima fica evidente que todas as diretrizes colocadas em prática para com a Universidade em Coimbra estão articuladas a um contexto maior, que circunscreve não apenas o Império lusitano, mas também as problemáticas religiosas e civis do século XVI. Ora, é essa a interpretação que fazemos quando o rei afirma que, pela necessidade de conservação e aumento da fé católica em seus reinos, era preciso haver letrados tanto no plano espiritual como no temporal, a fim de que pudessem ser enviados aos diversos territórios ultramarinos do Império português como, por exemplo, ao Brasil, para pregar, converter e ensinar os gentios e infiéis a fé, os costumes e conceitos do europeu católico português do 
século XVI. Foi por todos esses motivos, que dizem respeito também, mas não somente, ao reino português, que o rei justifica que ordenou fazer Universidade na cidade de Coimbra e empreendeu as diversas ações que tratamos ao longo desse trabalho.

Dessa forma, dividimos o texto em dois eixos centrais: I) Reorganização das finanças da Universidade, em que apresentamos as medidas de investimento financeiro na instituição; II) Contratação Docente, com a exposição da renovação pedagógica objetivada pela Coroa com a admissão de lentes para o Estudo.

\section{Reorganização financeira}

Em pesquisas anteriores, tivemos a oportunidade de perceber que a Universidade transferida da cidade de Lisboa para Coimbra em 1537 sofreu uma profunda e paulatina reorganização nos diversos setores que a constituía. Além das diretrizes emanadas da Coroa relativas à reorganização administrativa, tanto internamente quanto com o meio citadino que a cercava, o Estudo também sofreu diversas modificações pedagógicas que objetivavam readequar a formação propiciada pela instituição à sociedade do Império lusitano. Percebemos que esse mesmo processo de reorganização também foi o carro-chefe das ações da Coroa no que se refere ao setor financeiro da Universidade de Coimbra.

Nesse sentido, logo após a transladação, as primeiras notícias que temos sobre esse assunto podem ser constatadas no ano de 1538, quando o monarca escreve a Frei Diogo de Murça sobre a anexação das rendas das igrejas do morgado de Medelo à Universidade, “[...] por eu saber que as igrejas que andavam anexadas em vida do conde de Marialva por indevidas informações [...] determinei de as fazer aplicar as ditas rendas aos estudos que ordenei em Coimbra [...]" (DOCUMENTOS DE D. JOÃO III, 1937, vol. I, p. 102). De acordo com Almeida e Brandão (1937, p. 193 a 195), houve a anexação de muitas outras igrejas de diversas regiões do reino português às finanças da Universidade.

A anexação das rendas dessas igrejas deve ser analisada com mais cuidado para que possamos compreender quais poderiam ser os motivos que justificaram essas ações da Coroa para com a sociedade e a Universidade portuguesa. Dessa forma, uma carta de 25 de novembro de 1542, que permitiu a união da Universidade a várias igrejas, pode esclarecer quais os objetivos do poder real com essas diretrizes:

Dom João pela graça de Deus Rei de Portugal e do Algarve daquem e além mar em África, de Guine da conquista e navegação comércio da Etiópia, Arábia, Pérsia e da Índia faço saber aos que esta minha carta vierem e o pertencimento do caso pertencer que havendo eu respeito ao serviço de Deus e meu e bem da República de meus reinos e senhorios que se segue de em eles haver Estudos Gerais e como os ditos Estudos não podem ter mestres e lentes suficientes para ensinar e ler em eles sem terem renda de que os ditos mestres e lentes ajam suficientes salários, pedi ao Santo padre Paulo III ora na Igreja de Deus presidente, que houvesse por bem 
de unir e anexar para sempre aos Estudos que novamente ordenei na cidade de Coimbra as igrejas do Salvador do Crucifixo de Bouça bispado do Porto e da Santa Maria de Fonte Arcada e Santa Maria da Sardoeira e de São Martinho de Mouros do bispado de Lamego com suas anexadas; e Sua Santidade a minha instância houve por bem de anexar para sempre as ditas igrejas ao dito Estudo como dito é com tanto que eu desse meu consentimento sendo elas ou algumas delas de meu padroado, eu pelos ditos respeitos ou o meu consentimento e ei por boa e valiosa a dita união per sua Santidade feita das ditas igrejas ao dito Estudo na forma e modo que na dita bula se contém. Quanto com direito devo e posso e enquanto a mim e a Coroa de meus reinos e padroado da ditas igrejas pertence e ei por bem que a dita união se cumpra e guarde e haja cumprimento feito para guarda e conservação dos ditos Estudos [...] (DOCMENTOS DE D. JOÃO III, 1938, vol. II, p. 108, sem grifos no original).

Nos trechos em destaque da carta, chamamos a atenção para as razões expostas pelo monarca para que ocorresse a anexação das rendas dessas igrejas às finanças da Universidade. Como fica claro, o monarca justifica a incorporação dessas rendas pela necessidade de haver no reino uma Universidade com lentes competentes nas ciências daquela época. Esses mestres, cuja tarefa está relacionada à formação de letrados que auxiliassem na governança da sociedade, só podem desempenhar com satisfação sua tarefa se lhes forem concedidos "suficientes salários" para manter sua sobrevivência e competência acadêmica. Nesse sentido, o rei solicita ao Papa a anexação dessas igrejas à Universidade, igrejas essas que faziam parte, também, do Padroado Real. Com o consentimento pontifício, a Coroa repassa ao Estudo essas rendas com a declaração da ação ser "boa e valiosa" aos seus reinos.

Embora desde o início da vida da Universidade na cidade de Coimbra a Coroa tenha procurado dotar e oportunizar condições financeiras para sua subsistência, percebemos que, em razão das despesas da reforma, essas diretrizes não foram suficientes. É isso que presumimos por meio da carta enviada ao rei por Doutor Martin de Azpiculeta Navarro: "[...] as rendas que $\mathrm{V}$. A. tem feito mercê a esta universidade nom bastam para o pagamento dos lentes e outros guastos necessarios assi porque ellas são poucas como porque o rendeiros que a ellas são obriguados nom paguam aos tempos devidos" (apud FONSECA, 1997a, p. 448). É nesse sentido, de escassez de recursos financeiros, que entendemos as negociações empreendidas pelo poder real junto ao Papa para a incorporação das rendas do priorado mor de Santa Cruz a Universidade no início da década de 1540.

Sobre esse tema, encontramos duas cartas datadas de 17 de novembro de 1543 , em que o monarca escreve ao seu embaixador em Roma, Baltazar de Faria, acerca da ordem de intercessão perante o Papa sobre o seu desejo e objetivo dessa anexação ao Estudo:

[...]E, como sabeis, a dita Universidade é causa muito necessária e muito proveitosa a estes meus reinos e senhorios por o defeito que até agora houve de letrados, maiormente os eclesiásticos; e a dita Universidade não se pode sustentar sem ter renda: pelo o que peço a Sua Santidade 
que queira anexar os direitos e rendas do dito priorado mor de Santa Cruz à dita Universidade, como largamente vereis pela instrução que sobre isso vos envio. Vos falareis a Sua Santidade tanto que a esta for dada, por que é perigo na tardança, lhe dareis do assim vos escrevo, e muito afincadamente lhe pedireis de minha parte por serviço de Deus e bem da republica assim eclessiastica como secular, destes reinos, queira conceder a dita anexação e união como por minha parte se lhe pede [...] (DOCUMENTOS DE D. JOÃO III, 1938, vol. II, p. 150, sem grifos no original).

Nessa carta o monarca dá diversas instruções ao embaixador de Portugal em Roma, Baltazar de Faria, acerca da solicitação que deveria ser dirigida ao Papa sobre a anexação das rendas pertencentes ao Mosteiro de Santa Cruz à Universidade. Nela, novamente, é explicitada toda a problemática que envolve os objetivos da Coroa relacionados a essa solicitação. O rei declara que suas ações vinculavam-se à defasagem na formação de letrados que, mediante o desempenho de suas funções no reino, colaboravam para o seu governo. Essa falha na formação de letrados é relatada por D. João III especialmente no tocante aos eclesiásticos. Essa afirmação do rei pode ser relacionada aos diversos investimentos realizados no início do seu governo na concessão de bolsas de estudos aos centros de ensino teológico, em colégios e universidades francesas e espanholas.

A outra carta enviada nessa mesma data a Baltazar Faria também se torna importante para compreendermos os motivos que levaram a Coroa a não apenas solicitar essa anexação, mas também a reformar a Universidade do reino:

[...] pede sua Alteza a sua Santidade que para serviço de Deus e aumento da fé católica e da República desses reinos assim eclesiástico como secular haja por bem de anexar e aplicar todos os direitos rendas lugares bens e propriedades e pertenças do dito mosteiro de S. Cruz que pertença ao prior mor e a sua mesa assim e do modo que lhe pertencem a dita Universidade de Coimbra para serem regidos e governados e administrado pelo reitor e conselho da dita Universidade e os frutos se converteram nos pagamentos dos salários dos ditos lentes como governam e ministram os outros direitos e rendas da dita Universidade havendo respeito ao grande serviço de Deus que se segue de haver letrados em Teologia e Cânones e Leis para doutrinarem e governarem e regerem a republica cristã desses reinos assim no eclesiástico como no secular [...] (DOCUMENTOS DE D. JOÃO III, 1938, vol. II, p. 155 e 156).

Essa carta contém diversas instruções ao embaixador em Roma sobre quais argumentos deveria utilizar perante o Papa para obter o pedido de anexação solicitado pelo rei de Portugal. Nela são apresentadas diversas justificativas que Baltazar Faria deveria utilizar como, por exemplo, relatar ao Papa a falta de letrados, principalmente eclesiásticos, para aumento e conservação da fé católica; as despesas que o monarca tinha para manter lentes nas 
Ciências Sagradas com seus "gordos salários" e o serviço a Deus e a sociedade que a formação de letrados pela Universidade poderia proporcionar.

Podemos verificar que as justificações oferecidas pelo poder real ao Papa, por meio dos serviços de seu embaixador, vão muito além das necessidades práticas e financeiras que a Universidade tinha no que se refere aos recursos existentes para sua sobrevivência. Nessas duas cartas percebemos que os motivos elencados pela Coroa de anexar as rendas do Mosteiro de Santa Cruz ao Estudo relacionam-se diretamente com os objetivos de tornar a instituição um centro de referência na formação cultural, religiosa e científica do seu Império "para doutrinarem e governarem e regerem a republica cristã desses reinos assim no eclesiástico como no secular".

Diante desses rendimentos obtidos pela Coroa junto ao Papa era necessário, também, criar mecanismos para que tudo fosse administrado pela própria Universidade. É dessa forma que podemos entender o alvará de 12 de dezembro de 1548 sobre a administração da fazenda da Universidade:

Eu el Rei faço saber a vos reitor lentes deputados e conselheiros da minha Universidade de Coimbra que eu ei por bem e me apraz que a fazenda dessa Universidade assim a que foi do priorado mor de Santa Cruz como toda outra que ora lhe pertence e ao diante pertencer seja regida e governada pelo modo seguinte para melhor despacho das partes e mais proveito da Universidade.

Haverá nas Escolas Gerais uma casa em que haverá uma mesa para os despachos na qual se ajuntaram dois dias em cada semana ou mais se necessário for o Reitor com Pero Dias vereador da fazenda, e com Diogo de Azevedo escrivão do conselho e Simão de Figueiro escrivão da fazenda que foi do priorado e o lente Estevão Nogueira sindico e dois deputados lente que para isso eu nomear [...] (DOCUMENTOS DE D. JOÃO III, 1939, vol. III, p. 191 e 192).

Esse alvará versa sobre como a Universidade deveria proceder a partir daquele ano em diante para administrar as suas posses: rendas, igrejas, terras, matas, mantimentos, entre outras formas de rendimentos. Nele encontramos referências para a organização de todos os rendimentos pelos membros do Estudo, com a enumeração das diversas tarefas que a junta deveria realizar na administração da fazenda da Universidade. Nos diversos itens que compõem esse alvará, percebemos que a Coroa passa a delegar a administração da fazenda e a organização interna da instituição à própria Universidade, assim como havia declarado nas cartas enviadas a Roma para a anexação das rendas do Mosteiro de Santa Cruz.

Se nesse alvará de 1548 encontramos a primeira alusão sobre a criação desse órgão, nos Estatutos de 1559 também encontramos referências sobre a administração da fazenda da Universidade. No capítulo 20 do referido documento são dispostas as mesmas tarefas 
delegadas no alvará de 1548, a diferença reside na inserção de algumas novas funções e tarefas que objetivavam adequar esse órgão às circunstâncias da Universidade.

Nesta seção, que tratamos da reorganização financeira da Universidade, buscamos mostrar algumas medidas empreendidas pela Coroa no período de 1537 a 1559 para organizar e remodelar as questões relacionadas às finanças do Estudo. Para melhor compreensão do objetivo central do presente trabalho passemos a analisar a contratação docente.

\section{Contratação docente}

No que se refere às lentes da Universidade, encontramos, nos documentos de D. João III sobre o Estudo de Coimbra, diversas cartas e alvarás que se referem à nomeação e à contratação de professores. Isso se deve à renovação do quadro docente com a substituição de quase todos os professores da Universidade de Lisboa por nacionais ou estrangeiros, convidados pela Coroa para as cadeiras oferecidas no Mondego.

Dessa forma, percebemos que nos anos iniciais foram remetidas à Universidade, sempre nos meses de setembro ou outubro, diversas nomeações de lentes para as cadeiras oferecidas nos cursos, com a estipulação de pagamentos diretamente pela Coroa. Essas nomeações ocorriam nessas datas em razão do ano letivo ter início em $1^{\circ}$ de outubro.

Algumas contratações eram efetuadas com tempo estipulado de um, dois e no máximo seis anos. Entretanto, havia também aquelas em que o monarca contratava de forma permanente, como é o caso de Martin Aspicuelta Navarro², doutor lente da cadeira de Prima da faculdade de Cânones, e Pedro Nunes, para a cadeira de Matemática.

Outra medida utilizada pela Coroa para reformar a Universidade portuguesa pode ser verificada na comunicação mantida entre o monarca e seus embaixadores em outros reinos, em especial em Roma, com o embaixador Baltazar de Faria. Percebemos que, no início da década de 1540, a Coroa já diligenciara algumas ações para contratar lentes cujo requisito essencial era seu prestígio em terras estrangeiras. A primeira vez que temos essas notícias datam de 1540.

[...] Acerca do lente para a Universidade de Coimbra sobre o que vos falei quando partistes de que a me respondestes que vos avises de ver com ele para lhe falardes até agora não tenho visto outra resposta vossa acerca disso muito vos encomendo que pelo primeiro que me escrevais o que nisso tendes feito [...] (DOCUMENTOS DE D. JOÃO III, 1938, vol. II, p. 159).

\footnotetext{
${ }^{2}$ Almeida (1997, p. 825) ao discorrer sobre a vinda para Coimbra de Martin Azpilcueta, conhecido como Doutor Navarro, por ser proveniente dessa região do reino espanhol, estava relacionada às intervenções de Carlos $\mathrm{V}$, junto a D. João III. Almeida e Brandão (1937, p. 193) apresentam que "[...] Dr. Navarro, gabava-se de auferir ordenado superior a quanto até então se pagaram nas universidades de nossa Península ou da França; e na realidade tão elevado que até Clenardo o mencionava com espanto e despeito [...]”.
} 
Esse trecho refere-se a uma carta de D. João III a Baltazar de Faria, em que o monarca solicitava ao embaixador algumas informações que ainda não havia recebido sobre a contratação de determinado lente que não foi relatado na carta. A partir dessa data constatamos a existência de diversas cartas enviadas a Roma, em que o assunto a ser tratado refere-se à contratação de lentes estrangeiros, como fica patente na carta enviada em 15 de janeiro de 1545.

Doutor Baltazar Faria, eu el Rei vos envio muito saudar. Bem creio que sereis lembrado do que os dias passados me escrevestes acerca do letrado que vos encomendei que buscasses lá para vir a ler na Universidade de Coimbra, e do que eu vos respondi a isso. Até agora não tenho visto resposta vossa, nem sei o que mais nisso fizestes; e porque eu folgaria de me escrevestes, pela necessidade que há de na dita Universidade haver hum letrado muito suficiente, e que nela possa fazer com suas letras o fruto que desejo, vos encomendo muito que pelo primeiro correio me escrevais muito particularmente o que neste negócio tendes passado [...] (DOCUMENTOS DE D. JOÃO III, 1938, vol. II, p. 220).

Essa carta serve como exemplo para refletirmos sobre as intenções do rei, ou mais especificamente da Coroa, não somente para a contratação de lentes estrangeiros para a Universidade de Coimbra, mas para a reforma que estava sendo efetivada na instituição.

No trecho acima constatamos os interesses do monarca em ter notícias do que havia ordenado ao embaixador, a ponto de encomendar que "me escrevais muito particularmente o que neste negócio tendes passado". Outro dado que chama a atenção refere-se ao fruto que o lente a ser contratado deveria fazer na Universidade. Poderíamos indagar: Mas que frutos seriam esses? O que pretendia o monarca com a contratação de lentes estrangeiros para a Universidade de Coimbra?

Embora essa resposta não esteja explícita nas cartas que versam sobre esse assunto, podemos, mediante as análises de outras comunicações do monarca com o seu embaixador, conjecturar algumas hipóteses apresentadas na sequência deste texto. Nesse contexto, passemos a analisar mais uma carta que versa sobre a possível contratação do lente Marco de Mantua, também datada de 15 de janeiro de 1545 :

Doutor Baltazar Faria, eu el Rei vos envio muito saudar. Sebastião de Carvalho me escreveu de Roma que, por Antonio Barros lhe mandar dias passado recado a Pádua, onde então ele estava, que soubesse se naqueles Estudos havia algum bom letrado, que me quisesse vir servir nos Estudos de Coimbra, ele falará com um doutor Marco de Mântua, que é um dos melhores que naquelas partes havia assim em Leis como em Cânones, o qual lhe dissera que, mandando lhe eu dar em cada um ano o que fosse razão segundo o merecimento de suas letras, ele aceitaria vir me servir por alguns anos no dito estudo. E que a ele lhe parecia que, sendo eu servido de mandar acertar com ele vir me servir na dita Universidade por tempo de VI anos, e 
fazendo-lhe mercê em cada um desses anos de mil cruzados ele se contentaria disso e folgaria de me vir servir. E, por que eu folgaria que na dita Universidade houvesse pessoas de letras e suficientes, que nela fizessem o fruto que eu muito desejo, vos encomendo muito que, como esta vos for dada, vos informeis do dito Marco, e achando de suas letras e suficiências esta informação, e parecendo vos que poderei ser bem servido dele nos ditos estudos, enviareis logo a ele que logo se venha a mim [...] (DOCUMENTOS DE D. JOÃO III, 1938, vol. II, p. 221).

Nessa carta consta a negociação para a contratação de um lente para a Universidade. Nela, percebemos que a Coroa possuía informações de diversas localidades sobre os lentes que mais se destacavam no cenário acadêmico de algumas instituições. Além disso, podemos verificar como poderia ser o processo de contratação desses lentes mediante as ordens dadas ao embaixador caso se comprovassem as informações da Coroa. Novamente o rei relata o desejo de dotar a Universidade do reino com letrados competentes, a fim de que nela fosse possível colher os frutos que tanto desejava; frutos esses que, conjecturamos, estejam relacionados ao desenvolvimento das letras na Universidade de Coimbra.

Outra carta, de 11 de maio de 1545, dirigida a Frei Diogo de Murça, reitor da Universidade, também se relaciona a esse tema. Nela, podemos verificar que embora as contratações fossem sigilosas, eram de conhecimento da Universidade:

Padre reitor eu el Rei vos envio muito saudar vi a carta que me escreveste sobre o lente em Leis que a vos parecia que Seria meu serviço e bem da Universidade mandartes buscar a Itália par ler nela e porque eu receberia disso muito contentamento e folgaria de ver na dita Universidade tais lentes como convém e são necessários para a perfeição do que eu desejo [...] Me parece muito bem mandar logo a isso uma pessoa que possa falar com cada um de que em vossa carta nomeaste pois segundo a informação de que tenho são os mais principais de que agora há na Itália [...] (DOCUMENTOS DE D. JOÃO III, 1938, vol. II, p. 244 e 245).

Constamos que a Universidade pode ter feito a indicação de alguns lentes para serem contratos pela Coroa. Para tanto, o monarca ordena que um membro do Estudo em específico, Diogo de Azevedo, tenha a função de ir à Itália tratar das negociações dos lentes sugeridos pelo reitor. Essa ação do monarca pode estar relacionada a não efetivação das contratações que foram ordenadas a Baltazar Faria, pois em algumas cartas percebemos a insatisfação do monarca com a falta de notícias referentes a esse assunto, como, por exemplo, na correspondência de 13 de agosto desse mesmo ano.

[...] Pelo correio mor vos escrevi sobre um homem letrado, que desejava que viesse a ler na Universidade de Coimbra, e assim o tinha feito antes do correio mor; e até agora não tenho visto nenhuma resposta vossa acerca 
disso, nem sei disso o que tendes feito. Encomendo-vos muito que me escreva muito particularmente e me aviseis de tudo o que nesse caso for passado, para eu saber o que compre a meu serviço que nisso faça [...] (DOCUMENTOS DE D. JOÃO III, vol. II, 1938, p. 262).

Nessa carta visualizamos que o rei volta a solicitar ao embaixador que lhe envie notícias sobre a contratação de professores para a Universidade portuguesa. Podemos inferir que a função delegada a Diogo de Azevedo está relacionada ao não alcance dos objetivos da Coroa frente aos serviços prestados por Baltazar Faria ${ }^{3}$, em razão de servir o rei de Portugal em todos os assuntos relacionados à embaixada portuguesa em Roma.

As diretrizes da Coroa em contratar professores de renome em terras estrangeiras para a Universidade portuguesa se fizeram chegar até ao Papa Paulo III, quando o monarca escreve ao Pontífice para solicitar a liberação de um lente, em dezembro de 1546.

Muito Santo em Cristo Padre etc. Pela grande necessidade de que havia na Universidade que ora novamente fundei na cidade de Coimbra de lentes em Direito Civil de que nele lessem tão doutos como convinha mandei um criado meu a Itália buscar algum que quisesse vir ler a dita Universidade na dita faculdade, no qual concorressem as qualidades para que isso se requeriam. E agora me escreveu que tinha assentado com um que se chama Julio Radino de que me escreve muita boa informação, e que para poder vir cumpria dar lhe Vossa Santidade para isso licença. E porque tenho por muito certo que será servido de lhe dar assim pela necessidade de que eu dele tenho como pelo contentamento que eu receberei dele vir, lhe peço muito por mercê que lha queira dar com aquela denignidade que eu espero, no que receberei de Vossa Santidade muita singular mercê, como mais largamente de minha parte lhe dirá o reverendíssimo cardeal Santo Frol, a que me remeto (DOCUMENTOS DE D. JOÃO III, vol. IV, 1941, p. 357).

O rei solicita ao $\mathrm{Papa}^{4}$ a mercê referente à liberação do lente Julio Rabino em razão das qualidades que este possuía para servi-lo na Universidade reformada da cidade de Coimbra. Para tanto, o rei conta com o apoio de cardeal Santo Frol que iria interceder e explicar ao Pontífice as razões para a licença do dito mestre.

Todavia, constatamos as dificuldades enfrentadas por esses representantes da Coroa para conseguir recrutar lentes para levar para Portugal. Em carta de 2 de abril de 1547, além do descontentamento do monarca frente os serviços prestados por Diogo de Azevedo, verificamos essa questão:

\footnotetext{
${ }^{3}$ CDVII- 7 de Maio de 1546: Carta para o embaixador em Roma anunciando a partida para a Itália de Diogo de Azevedo Coutinho para tratar da vinda para Coimbra de lentes italianos (DOCUMENTOS DE D. JOÃO III, 1939, vol. III, p. 17 e 18).

4 Em outros documentos verificamos a comunicação da Coroa portuguesa com o Papa. Conferir: (DOCUMENTOS DE D. JOÃO III, 1941, vol. IV, p. 415).
} 
Diogo de Azevedo eu el Rei vos envio muito saudar vi a carta que me escrevestes de VIII de fevereiro em que me dais conta do que é passado acerca do negócio dos letrados a que vos mandei, e desaprova-me muito de haver nele tanto impedimentos e embaraços, e de que aqueles com que falastes tão mal vos cumpriem o que com eles acertaste. E por certo tenho por mingoa de vossa boa diligencia não vos ficara nisso nada por fazer. E pois micer Fabio Arcas de Varnia que esta em Alemanha sobre o que me agora escreveis tendes tão boa informação, e esperareis tão cedo seu recado, folgarei de asentares logo com ele, e de o trazerdes e assim os outros o mais cedo que poder ser: o que vos encomendo muito que o façais, porque receberei com isso muito contentamento e me haverei por muito servido de vos. E no fato de micer Ascanio Escoto e do teólogo se provera logo para que se ponha a todo bom recado [...] (DOCUMENTOS DE D. JOÃO III, 1941, vol. IV, p. 358 e 359).

Como fica explícito na carta, havia algumas dificuldades enfrentadas pelos agentes da Coroa portuguesa para conseguir enviar para o reino os letrados requisitados pelo rei. Muitos inicialmente aceitavam, mas depois desistiam da contratação. Na carta também fica registrado o processo de contratação de Fabio Arcas, que se tornou lente da Universidade portuguesa. Por fim, o monarca ordena o regresso de Diogo de Azevedo com os professores contratados para Portugal.

Ramalho (1997, p. 697), ao escrever sobre as contratações realizadas nesse período, pontua que a Universidade de Coimbra era "[...] uma escola verdadeiramente cosmopolita no respeitante ao seu corpo docente, pois os próprios portugueses que ensinavam na Universidade ou o Colégio das Artes [...] tinham sido bolseiros do rei no estrangeiro, na sua maioria na França e na Espanha [...]". Juntamente com os lentes nacionais havia, em número até maior, os estrangeiros. Ramos (1997, p. 74) explica a causa como sendo “[...] Precisamente porque havia dinheiro, entre os mestres abundavam os estrangeiros, formados nos grandes centros universitários europeus, [...]". Além dos salários elevados pagos aos lentes da Universidade de Coimbra, observamos que houve também a criação de condições de habitação, abastecimento alimentício e privilégios especiais destinados aos lentes das cadeiras grandes.

Como ficou constatado em pesquisas anteriores, a Universidade sempre teve autonomia para escolher seus professores. Todavia, verificamos que essa autonomia começa a demonstrar algumas fraquezas na medida em que caminhamos rumo à modernidade. Conforme argumenta Fonseca (1997b, p. 506): “O concurso era a acesso normal a um limitado quadro de docentes; mas, num primeiro momento, logo após a transferência da Universidade para Coimbra, a acção directa do monarca, através de convite, desempenhou um papel preponderante na constituição do corpo de professores [...]". Isso fica evidente quando analisamos os diversos documentos, cartas e alvarás encaminhados à Universidade portuguesa nesse período. Para o autor, essa forma de provimento estava relacionada com a intenção de "[...] dotar as cadeiras de maior responsabilidade com professores de créditos firmados [...]", 
já que em diversos momentos foi constatado o suborno e a compra de cargos na Universidade, antes da transferência definitiva para a cidade do Mondego.

Ao findarmos este artigo, cabe apresentarmos a concepção expressa em Almeida e Brandão (1937, p. 212) sobre os lentes da Universidade: "A despeito do que determinava os estatutos o provimento das cátedras foi nessa época da livre nomeação do monarca, a não ser de uma ou outra catedrilha, em como a escolha dos substitutos, que continuou pelo conselho". Dessa forma, verificamos que apesar de nos Estatutos de D. Manuel, que regeram a Universidade até 1544, e nos Estatutos de 1559 constar todo o processo para o provimento das cadeiras, grandes e pequenas da Universidade, no período delimitado deste trabalho esses provimentos ocorreram pela nomeação do poder real.

\section{Considerações Finais}

De tudo o que foi dito até o momento, acreditamos que a reforma da Universidade, no século XVI, além de estar relacionada às problemáticas da organização civil e religiosa do próprio reino de Portugal, também estava vinculada às questões do Império ultramarino no campo temporal e espiritual.

Da reforma empreendida, o que chamamos a atenção nesse artigo refere-se a duas diretrizes da Coroa portuguesa para com a Universidade de Coimbra, presente na documentação utilizada: reorganização financeira e contratação docente.

No que se refere à reorganização financeira, verificamos que o poder real empreendeu diversas medidas no sentido de subsidiar financeiramente as atividades docentes da Universidade. Se em um primeiro momento as ações da Coroa se restringiram a repassar à instituição as rendas de algumas igrejas, paulatinamente, o poder real criou um órgão próprio responsável pela administração dos bens da dita instituição.

A segunda diretriz analisada diz respeito à contratação docente, em que percebemos alguns encaminhamentos emanados da Coroa para readequar o quadro docente da Universidade aos objetivos da reforma. Entre esses encaminhamentos destaca-se a rede de informações estabelecida pelo poder real lusitano em outros reinos, a fim de obter informações de lentes que mais se destacavam no cenário acadêmico. O objetivo era trazer para Portugal esses docentes para lecionarem em Coimbra.

Acreditamos, e isso fica evidente nos documentos aqui apresentados, que os objetivos das diretrizes da Coroa portuguesa para com a reforma da Universidade de Coimbra estendiam-se para o território ultramarino, tanto em assuntos ligados ao governo espiritual como ao temporal. Podemos considerar que foi no reinado de D. João III que a Universidade portuguesa passou por uma profunda reforma que de fato consolidou a instituição como centro de formação dos quadros profissionais do reino, seja nos negócios relativos ao poder real ou espiritual. 
Percebemos que a análise da reorganização financeira e contratação docente colabora na compreensão dos objetivos do poder real para reformar a Universidade, a fim de torná-la um centro de formação intelectual e religioso de todo o Império lusitano.

\section{Referências}

ALMEIDA, M. J. O Direito (Cânones e Leis). História da Universidade em Portugal (1537-1771). Vol. I, Tomo II. Coimbra: Universidade de Coimbra e Fundação Calouste Gulbenkian, 1997.

ALMEIDA, M. L. \& BRANDÃO, M. A universidade de Coimbra: esboço de sua historia. Coimbra: Oficinas Gráficas Atlânticas, 1937.

BLOCH, M. Apologia da História, ou o ofício de historiador. Trad. de André Telles. Rio de Janeiro: Jorge Zahar, 2001.

DOCUMENTOS DE D. JOÃO III. Volume I. Publicado por Mário Brandão. Coimbra, 1937.

DOCUMENTOS DE D. JOÃO III. Volume II. Publicado por Mário Brandão. Coimbra, 1938.

DOCUMENTOS DE D. JOÃO III. Volume III. Publicado por Mário Brandão. Coimbra, 1939.

DOCUMENTOS DE D. JOÃO III. Volume IV. Publicado por Mário Brandão. Coimbra, 1941.

ESTATUTOS DA UNIVERSIDADE DE COIMBRA (1559) com introdução e notas históricas e círiticas de Serafim Leite. Coimbra: Por Ordem da Universidade, 1963.

FONSECA, F. T. As finanças (Universidade de Coimbra). IN: História da Universidade em Portugal (1537-1771). Vol. I, Tomo II. Coimbra: Universidade de Coimbra e Fundação Calouste Gulbenkian, (1997a).

FONSECA, F. T. Universidade de Coimbra. IN: História da Universidade em Portugal (1537-1771). Vol. I, Tomo II. Coimbra: Universidade de Coimbra e Fundação Calouste Gulbenkian, (1997b).

MONTESQUIEU, C. L. S. O espírito das leis.Tradução de Fernando Henrique Cardoso e Leôncio Martins Rodrigues. Brasília: UNB, 1995, p. 443- 475. 
RAMALHO, A. C. O humanismo depois de 1537. História da Universidade em Portugal (1537-1771). Vol. I, Tomo II. Coimbra: Universidade de Coimbra e Fundação Calouste Gulbenkian, 1997.

RAMOS, L. A. O. A Universidade de Coimbra. IN: História da Universidade em Portugal (1537-1771). Vol. I, Tomo II. Coimbra: Universidade de Coimbra e Fundação Calouste Gulbenkian, 1997.

TEIXEIRA, A. Ensino superior no Brasil: análise e interpretação de sua evolução até 1969. Rio de Janeiro: FGV, 1989.

Recebido em: 12/02/2014

Revisado em: 14/06/2014

Aprovado para publicação em: 07/07/2015

Publicado em: 31/08/2016 